\title{
Comprometimento e Entrincheiramento Organizacionais: Uma Análise Comparativa com duas Instituições de Ensino Superior
}

\section{Commitment and Organizational Entrenchment: A Comparative Analysis with two Institutions of Higher Education}

\author{
Rogério Castro Destêrro e Silva ${ }^{1}$, Gean Carlos Tomazzoni², Vânia Medianeira Flores Costa ${ }^{1}$ \\ ${ }^{1}$ Universidade Federal de Santa Maria, UFSM, Brasil, ${ }^{2}$ Universidade Federal do Rio Grande do Sul, URGS, Brasil. \\ Correspondência: Gean Carlos Tomazzoni. Rua Washington Luiz, 855, Centro Histórico, CEP 90.010-460, Porto \\ Alegre, RS, Brasil. Telefone: +55 (51) 3308-3675. E-mail: gean.tomazzoni@ hotmail.com.
}

Recebido: 25 de março de 2018 Aceito: 02 de outubro de 2018 Publicado: 28 de dezembro de 2018

DOI: http://dx.doi.org/10.21714/1679-18272018v16n1.p57-68

\begin{abstract}
Resumo
Este estudo tem por objetivo comparar a percepção dos técnico-administrativos em educação de duas instituições de ensino superior acerca do estabelecimento dos vínculos de comprometimento e entrincheiramento com as suas organizações. Para tanto, realizou-se um estudo de natureza descritiva com a participação de duas instituições federais de ensino superior: IES A localizada no estado do Maranhão e IES B localizada no estado do Rio Grande do Sul. A amostra da pesquisa foi de 242 indivíduos da IES B e 139 da IES A. A partir dos resultados foi possível verificar que o comprometimento apresentou níveis elevados nas duas instituições pesquisadas, o que revela uma vinculação emocional dos empregados com suas instituições. Os níveis de entrincheiramento organizacional demonstraram-se altos na IES A e moderados na IES B. Em síntese os resultados confirmam a coexistência dos vínculos de comprometimento e entrincheiramento nos servidores das duas instituições. Depois de um longo período em que a pesquisa sobre os vínculos do trabalhador com a organização esteve focada, quase que exclusivamente, no construto do comprometimento, a nova perspectiva de múltiplos vínculos organizacionais é reforçada com os resultados desta pesquisa.
\end{abstract}

Palavras-chave: Vínculos Organizacionais, Comprometimento, Entrincheiramento.

\begin{abstract}
This study aims to compare the perception of the technical-administrative in education of two higher education institutions about the establishment of ties of commitment and entrenchment with their organizations. A study of a descriptive nature was carried out with the participation of two federal higher education institutions: IES A located in the state of Maranhão and IES B located in the state of Rio Grande do Sul. The research sample was 242 individuals from HEI B and 139 from the IES A. From the results it was possible to verify that the commitment showed high levels in the two researched institutions, which reveals an emotional connection of the employees with their institutions. Organizational entrenchment levels were shown to be high in HEI and moderate in HEI B. In summary, the results confirm the coexistence of commitment and entrenchment links in the servers of the two institutions studied. After a long period in which the research on the worker's ties with the organization was focused almost exclusively on the commitment construct, the new perspective of multiple organizational ties is reinforced with the results of this research.
\end{abstract}

Keywords: Organizational Ties, Commitment, Entrenchment.

Esta obra está licenciada sob uma Licença Creative Commons Attribution 3.0.

\section{Introdução}

Os vínculos estabelecidos pelo indivíduo com o seu trabalho e a sua organização vêm passando por consideráveis transformações, especialmente a partir dos anos 80 do século XX, quando o processo de globalização passou a exigir mais das organizações, e estas, por sua vez, passaram a buscar mais profissionais qualificados e responsáveis pelo desenvolvimento cultural, social, econômico e ambiental, adaptáveis às constantes mudanças de cenários (RODRIGUES; BASTOS; GODIM, 2013).

O comprometimento organizacional, tanto no cenário internacional quanto no nacional, mantém-se entre os tópicos 
mais investigados no domínio do comportamento organizacional. As expectativas sobre os efeitos que a intensidade do comprometimento pode gerar nos próprios indivíduos, nas organizações e, por extensão, na sociedade como um todo, explicam o interesse científico, social e empresarial em estudá-lo. O comprometimento, como um fenômeno organizacional, permite unir pessoas em torno de qualquer empreendimento coletivo, bem como potencializar as chances de as organizações enfrentarem, com êxito, as transições e turbulências atuais, justificando, assim, as pesquisas nesta área (BASTOS; AGUIAR; BRITO, 2011).

Esse interesse motivou a realização de diversos estudos, considerando diferentes focos (organização, carreira, trabalho, profissão, objetivo, sindicato, entre outros) e bases do comprometimento (afetivo, instrumental, calculativo, normativo, afiliativo, etc.). A diversidade abrange questões conceituais e de mensuração que, apesar da longa trajetória de pesquisa, ainda são atuais desafios para os pesquisadores. Diante da redundância conceitual e dimensional do comprometimento, emergiu novos fenômenos visando maior compreensão e caracterização do vínculo estabelecido entre o trabalhador e a organização, como o entrincheiramento.

O entrincheiramento organizacional tem suas origens no campo de estudos de carreiras, liderado pelos estudos de Carson, Carson e Bedeian (1995), ao referir-se à condição que o trabalhador se coloca de continuar na mesma linha de atuação profissional em razão de alguns fatores, entre os quais: falta de opção, sensação de perda de investimento despendido com a carreira e a percepção de que a mudança lhe causará um dano emocional muito alto. No contexto organizacional, o entrincheiramento é conceituado como a tendência do indivíduo em permanecer na organização devido a possíveis perdas de investimentos e custos associados à sua saída e a percepção de poucas alternativas no mercado de trabalho (RODRIGUES; BASTOS, 2012).

Grande parte dos estudos sobre entrincheiramento, tanto na carreira como na organização, é vinculada ao tema comprometimento. Na verdade, os dois construtos possuem uma relação umbilical, na medida em que apresentam vários aspectos em comum, tais como: sacrifício, investimento pessoal, além do componente da escolha pessoal de permanecer na organização, configurando o que Rodrigues (2009) denomina de vínculo material e uma permanência por necessidade no entrincheiramento e vínculo emocional no comprometimento.

Apesar da noção de entrincheiramento estar relacionado a do comprometimento, por ambos representarem um estado psicológico que caracteriza a relação do indivíduo com a organização (MEYER; ALLEN, 1991), os estudos têm comprovado que se trata de vínculos organizacionais distintos, com preditores e consequentes também distintos (TOMAZZONI, 2017; PINHO, BASTOS; ROWE, 2015). O comprometimento, conforme explica Tomazzoni (2017), está associado a maiores índices de produtividade, motivação e empenho no trabalho, enquanto que a noção de entrincheiramento está associada a menores índices de produtividade e desmotivação da equipe. Ainda, para esse autor, indivíduos entrincheirados não são trabalhadores improdutivos, entretanto eles exigem um suporte maior da organização e dos gestores para que consigam desempenhar suas atividades com êxito.

Perpassando pela realidade das universidades federais, foco deste estudo, a partir de 2006, com a implementação do Plano de Desenvolvimento da Educação (PDE), que contém programas voltados para a expansão do ensino superior no Brasil, a exemplo do Programa de Apoio a Planos de Reestruturação e Expansão das Universidades Federais (REUNI), o quadro de servidores das universidades apresentou significativo crescimento, necessário para suprir à expansão das atividades, exigindo um olhar atencioso sobre a gestão de pessoas nessas instituições (TOMAZZONI et al., 2017). Andrade et al. (2014) acreditam que o momento de expansão no qual as universidades passam pode ser "frutífero", desde que haja um bom aproveitamento do quadro de servidores.

Diante disso, o desenvolvimento deste estudo justifica-se pois visa dar sua contribuição teórica e também prática para beneficiar a gestão de pessoas, ao analisar os vínculos de comprometimento e entrincheiramento, comparando duas Instituições de Ensino Superior Brasileiras de regiões e de realidades diferentes do país. Essas instituições obedecem às diretrizes do governo e preocupadas com a qualidade dos serviços públicos, prescrevem em seus Planos de Desenvolvimento Institucional a permanente necessidade de melhoria do desempenho dos seus servidores, pois têm um compromisso com o ensino, pesquisa e extensão dentro da sociedade brasileira, no tocante à incorporação de novas práticas de gestão de pessoas, geradoras de medidas que possibilitarão ampliar o comprometimento dos seus servidores, no resgate da sua imagem de instituições inovadoras indispensáveis à comunidade e ao desenvolvimento do Brasil.

Diante do exposto, este estudo tem por objetivo comparar a percepção dos técnico-administrativos em educação de duas instituições de ensino superior acerca do estabelecimento dos vínculos de comprometimento e entrincheiramento com as suas organizações.

\section{Comprometimento Organizacional}

Bastos (1994) conceitua comprometimento, afirmando que o mesmo envolve desejo de permanecer, sentimento 
de orgulho por pertencer à organização, identificação, apego, envolvimento aos valores, engajamento, empenho e esforço. No entendimento de Kanter (1968), comprometimento é a disposição para ceder energia e lealdade aos sistemas sociais, de modo que interesses individuais se atrelem aos padrões de comportamento. Assim, a noção de comprometimento organizacional adquire importância em diversas pesquisas (AYREE; CHAY; CHEW 1994; CARSON; CARSON; BEDEIAN, 1995; BLAU, 2001; BLAU; HOLLADAY, 2006). O comprometimento representa envolvimento que uma pessoa tem com o seu trabalho, o sentimento de lealdade e a intenção de permanecer e de se esforçar para alcançar metas relacionadas ao desenvolvimento em favor da organização (TONIN et al., 2012).

Meyer e Herscovitch (2001) aduzem que, de uma forma geral, existem diversas definições de comprometimento, mas todas assumem que esse é uma força estabilizadora resultante de um estado ou esquema mental, que direciona e restringe o comportamento do indivíduo a determinado curso de ação relevante para um ou mais objetivos. Ao compreender essa relação que se estabelece com a organização, amplia-se o entendimento das diferentes atitudes e comportamentos tomados pelos empregados, bem como possibilita uma melhor compreensão da natureza dos processos psicológicos pelos quais as pessoas escolhem identificar-se com os seus objetivos e a forma com que lhes atribuem significado (TEIXEIRA, 1994), a fim de predizer comportamentos relevantes para o contexto organizacional (COHEN, 2003), tais como: o absenteísmo, a rotatividade e o desempenho. Segundo Muller et al. (2008) somente o comprometimento organizacional não parece garantir o sucesso e o alcance dos objetivos de uma empresa, porém um funcionário comprometido, se esforçará mais para atingir os objetivos da organização.

Para Morrow (1983), Reichers (1985) e Chimezie e Osigweh (1989), o desenvolvimento desse construto é marcado pela fragmentação de conceitos e medidas de comprometimento organizacional, apesar da tentativa de construção de modelos integrativos. Costa (2000) aponta que a diversidade de conceitos é proveniente da sociologia, psicologia e teorias organizacionais. Destacam-se na literatura, o Modelo Unidimensional proposto por Mowday, Porter e Steers (1979) e o Multidimensional por Meyer e Allen (1991). Este último modelo, composto pelas dimensões Afetiva, de Continuação e Normativa, passou a representar a síntese dominante nesse campo, sendo praticamente hegemônico nas investigações científicas sobre o tema, a partir da década de 1990. Segundo Costa (2007), no Modelo Unidimensional, o comprometimento organizacional é visto como uma atitude global frente à organização. Em uma visão multidimensional, o comprometimento é dividido em componentes que podem se referir a diversos focos como, por exemplo, os definidos por Reichers (1985): trabalho, chefia e alta administração.

Meyer e Allen (1991) organizaram, sob um mesmo construto, três importantes vertentes de pesquisa já existentes: a que priorizava a natureza afetiva do vínculo (representada pelo trabalho de Mowday, Porter e Steers, 1979); a que enfatizava a noção de trocas e side bets - oriunda dos trabalhos de Becker (1960) e Ritzer e Trice (1969) -, e a vertente que encara o vínculo a partir de uma perspectiva de dever ou de obrigação para com a organização, ideia presente nos trabalhos de Kanter (1968) e O'Reilly e Chatman (1986). Cada uma dessas vertentes estabeleceu as bases conceituais e operacionais de uma das dimensões que viria a ser denominada de Modelo Tridimensional do comprometimento organizacional, baseados na proposta de Meyer e Allen (1991), conforme apresentado no Quadro 1.

\begin{tabular}{|c|l|}
\hline Bases Conceituais & \multicolumn{1}{c|}{ Descrição } \\
\hline $\begin{array}{c}\text { Afetivo } \\
\text { (affective) }\end{array}$ & $\begin{array}{l}\text { Comprometimento como um apego à organização, resultante de experiências } \\
\text { anteriores que promovem sensação confortável dentro da organização e } \\
\text { competência no trabalho. }\end{array}$ \\
\hline $\begin{array}{c}\text { De continuação } \\
\text { (continuance) }\end{array}$ & $\begin{array}{l}\text { Envolve a avaliação dos custos associados à saída da organização, que } \\
\text { resulta da magnitude e do número de investimentos feitos pelo empregado } \\
\text { na organização e a falta de alternativas no mercado. }\end{array}$ \\
\hline $\begin{array}{c}\text { Normativo } \\
\text { (obligation ou normative) }\end{array}$ & $\begin{array}{l}\text { Relacionado à adesão às normas e aos objetivos da organização, a partir de } \\
\text { pressões normativas por ele introjetadas, que ocorrem no processo de } \\
\text { socialização primário e após a entrada na organização. }\end{array}$ \\
\hline
\end{tabular}

Quadro1: Modelo tridimensional do comprometimento

Fonte: Adaptado de Meyer e Allen (1991).

Posteriormente, Meyer e Allen (1997) elaboraram um modelo de antecedentes e consequentes do comprometimento, que diferencia determinantes distais (características pessoais, organizacionais, práticas de gestão e condições ambientais) dos determinantes proximais (experiências relacionadas ao trabalho, estados dos papéis desempenhados e contratos psicológicos). Após observarem a magnitude das relações investigadas em estudos anteriores, os mesmos autores passaram a defender que os distais exercem influência no comprometimento, sofrendo efeito mediador das variáveis proximais. O modelo proposto integra antecedentes e 
consequentes das três bases previstas no modelo tridimensional (afetiva, de continuação e normativa).

Meyer e Allen (1997) caracterizam os indivíduos das três dimensões da seguinte forma: indivíduos com um forte comprometimento afetivo permanecem na organização porque querem; com comprometimento instrumental permanecem porque precisam e aqueles com comprometimento normativo permanecem porque sentem que são obrigados.

\section{Entrincheiramento Organizacional}

Os primeiros estudos sobre entrincheiramento foram analisados tendo como foco a carreira, colocando em pauta a discussão dos motivos que levam a permanência do trabalhador na organização. De acordo com Carson, Carson e Bedeian (1995), o entrincheiramento na carreira, considerado um construto multidimensional, é composto por três principais componentes: investimento na carreira, custos emocionais e limitações de alternativas de carreira (RODRIGUES et al., 2013). A partir das pesquisas realizadas no campo de estudos de carreiras por Carson e Bedeian (1994) e Carson, Carson e Bedeian (1995), o construto entrincheiramento passou a ser tratado na literatura para diferenciar do construto do comprometimento com a carreira.

Para Carson e Bedeian (1994) e Carson, Carson e Bedeian (1995), entrincheiramento na carreira diz respeito à opção de continuar na mesma linha de ação profissional, por falta de opções, pela sensação de perda dos investimentos já realizados ou pela percepção de um preço emocional a pagar, muito alto, para mudar. Esses autores adotaram a mesma base teórica que é utilizada para tratar do comprometimento de continuação - a noção de troca instrumental introduzida por Becker (1960) -, a fim de fundamentar o sentido de trocas materiais embutidos no construto entrincheiramento. De acordo com Carson, Carson e Bedeian (1995), as consequências para indivíduos e organizações de "estar entrincheirado" na carreira poderão ser positivas ou negativas. Por um lado, indivíduos entrincheirados podem contribuir para uma maior estabilidade da força de trabalho e redução da rotatividade, por outro, se estiverem insatisfeitos, apresentam baixos níveis de motivação, negligência e falta de interesse em desenvolver novas habilidades.

Ferreira (2011) indica que estar entrincheirado na carreira não significa, necessariamente, que o trabalhador esteja insatisfeito. Na mesma linha de raciocínio, Rowe, Bastos e Pinho (2011) explicam que alguns profissionais podem estar satisfeitos com seu entrincheiramento, porque, embora sejam limitadas as suas escolhas da carreira, podem estar satisfeitos com seu desenvolvimento profissional e ganhos pessoais (salários, status social e outros fatores motivadores para o trabalho).

O vocábulo "trincheira" está associado a estratégias de guerra e proteção. Os soldados ficavam entrincheirados durante o combate, com o objetivo de aumentar a proteção e reduzir os danos de um possível ataque (FERREIRA, 1998). A transposição desse conceito para o contexto organizacional gera a interpretação de que o trabalhador entrincheirado busca em sua organização - a trincheira - uma forma de proteção, segurança, garantia de estabilidade, manutenção de seu status quo e evitação de outras perdas associadas à sua saída (BASTOS et al., 2008). Nesse sentido, o vínculo estabelecido entre indivíduo e organização não inclui desejo, mas sim necessidade. O trabalhador permanece na organização porque sua saída pode gerar danos maiores (RODRIGUES, 2009). Carson, Carson e Bedeian (1995) entendem por indivíduo entrincheirado aquele que se encontra estagnado na carreira, não apresentando aspectos de adaptabilidade ou motivação para encontrar alternativas para seu aprimoramento profissional. Essa estagnação ocasiona sintomatologias nos indivíduos, tanto em sua saúde física quanto mental, como tédio, monotonia, isolamento social, ressentimento, depressão, pessimismo, estresse e, ainda, sentimentos de inferioridade, mágoa e ofensa.

Associados a esses sintomas, outros fatores que podem contribuir para que o indivíduo permaneça entrincheirado são: o desejo de evitar o estigma social, o temor que a idade seja percebida como avançada para busca de uma nova colocação profissional, medo de perder privilégios já conquistados ou de colocá-los em risco em prol de uma possibilidade de adesão em uma nova atuação profissional (ROWE et al., 2011).

Rodrigues (2009) esclarece que, ao fazer uma confrontação com a teoria de Becker (1960), esses fatores poderiam ser chamados side bets, sendo este nome proposto para conceituar o comprometimento, e que essa teoria está na base de formação do construto de entrincheiramento. Na tradução para o português, bet significa "aposta" e side significa "lado". Assim, o indivíduo que aposta em determinado objetivo deve seguir um lado, uma direção consistente, uma lógica contínua de comportamento, restringindo as atividades que venham de encontro a esse objetivo inicial.

Para Rodrigues et al. (2013), o entrincheiramento organizacional engloba o tipo de vínculo instrumental que, até então, era atribuído ao comprometimento por meio da base de continuação. O indivíduo entrincheirado se mantém na organização por possuir um vínculo de necessidade, fica ligado à organização por não acreditar que haja outra 
opção que atenda suas necessidades e expectativas (RODRIGUES, 2009). É a permanência por necessidade e não por querer, não por gostar. Nesse sentido, Rodrigues (2009) propõe um modelo esquemático de entrincheiramento na organização, onde explica que o construto entrincheiramento organizacional é composto pelos seguintes fatores: ajustamentos individuais a posições sociais, arranjos burocráticos impessoais e limitação de alternativas.

Nos ajustamentos a posições sociais, tanto o profissional quanto a organização realizam investimentos a fim de que determinada atividade seja bem desenvolvida, e o trabalhador se adapte à posição em que se encontra (BECKER, 1960). Segundo Scheible e Bastos (2013), quando isso ocorre, os indivíduos não são motivados a considerar outras alternativas de trabalho. O comportamento do indivíduo é fixado de acordo com o papel social exigido, fica em uma posição confortável, acredita ter bom desempenho, é reconhecido por sua função na organização e ali permanece, entretanto, tudo o que aprendeu seria perdido caso abandonasse a empresa (RODRIGUES, 2009).

Quanto aos arranjos burocráticos impessoais, o profissional teme perder a estabilidade obtida, os ganhos financeiros e os benefícios adquiridos, como planos de saúde, odontológicos, aposentadoria, entre outros. Dessa forma, o trabalhador entrincheirado pressente que sua saída da organização lhe causará graves danos e, por isso, permanece trabalhando e não pelo fato de desejar contribuir para o crescimento da empresa (RODRIGUES, 2009).

No que diz respeito à limitação de alternativas, o indivíduo sente a sensação de estar entrincheirado na organização, devido à ausência de alternativas, pois verifica que não há espaço no mercado de trabalho, por conta da sua idade, limitação de conhecimentos etc. (RODRIGUES, 2009).

Estudos sobre entrincheiramento levam à interpretação de que o profissional entrincheirado busca, no seu trabalho a trincheira, uma forma de proteção, segurança, garantias de estabilidade e manutenção de seu status, ao mesmo tempo em que procura evitar perdas associadas à sua saída (RODRIGUES, 2009; SEGALA, 2013). O conceito de entrincheiramento, portanto, tem sua importância na medida em que coloca em evidência o vínculo desenvolvido pelo indivíduo em determinada profissão, função, cargo ou mesmo organização. É este vínculo que o mantém preso (como em uma trincheira) por não conseguir visualizar uma alternativa que atenda às necessidades $\mathrm{e}$ expectativas que ele considera vitais. É essa a essência do entrincheiramento, tanto com foco na carreira, como na organização.

\section{Método do Estudo}

O presente estudo caracteriza-se como uma pesquisa descritiva, com emprego de abordagem metodológica quantitativa, realizada por meio de um estudo de caso comparativo entre duas instituições federais de ensino superior brasileiras. Uma localizada no estado do Maranhão, denominada IES A, e outra localizada no estado Rio Grande do Sul, denominada IES B. Assim, cabe esclarecer que os dados referentes a IES B são provenientes do trabalho de Segala (2013), que foram analisados comparativamente com os dados coletados na IES A, visando atingir o objetivo desta pesquisa. A escolha das instituições para este estudo comparativo justifica-se por estarem em diferentes regiões do Brasil, com culturas e oportunidades distintas. São instituições inovadoras que estão despontando no cenário nacional, devido ao processo de expansão universitária que está ocorrendo por meio da ampliação do número de vagas, criação de novos cursos, implantação de cursos à distância e novos centros de ensino, em outras regiões do Estado do Rio Grande do Sul e do Estado do Maranhão. Também por serem instituições comprometidas com a melhoria da qualidade de vida do ser humano em geral, com o meio ambiente, com o ensino, a pesquisa e a extensão e por proporcionarem aos seus discentes, docentes e técnico-administrativos oportunidades de participarem de uma maior integração nacional em prol do desenvolvimento igualitário entre suas regiões.

Para fins de amostra, de acordo com Segala (2013), a aplicação dos questionários na IES B considerou as taxas de não retorno e realizou um cálculo amostral utilizando-se da técnica de amostragem probabilística aleatória, com um parâmetro de $95 \%$ de confiança em função do erro amostral (e) $=5 \%$, chegando a um total de 268 questionários. Por ser um comparativo, os mesmos procedimentos foram adotados na aplicação dos questionários na IES A. Considerando as taxas de retorno dos questionários foi realizado um cálculo amostral utilizando-se a técnica de amostragem probabilística aleatória, com um parâmetro de $95 \%$ de confiança em função do erro amostral (e) = $5 \%$, chegando a um total de 139 questionários a serem aplicados. Retornaram válidos 162 questionários. Assim, a população desta pesquisa foi composta dos servidores técnico-administrativos em educação, lotados nos centros de ensino das IES A (162) e IES B (268).

Para a coleta de dados utilizou-se um instrumento de pesquisa dividido em duas partes. A primeira parte do questionário denominada dados de identificação foi composta por quatro questões referentes aos dados ocupacionais e pessoais dos respondentes. A segunda parte do questionário, denominada comprometimento e entrincheiramento organizacionais, é constituída pelo modelo de avaliação de comprometimento e entrincheiramento proposto por Bastos et al. (2011) e Rodrigues (2009), respectivamente, composta de 46 itens. A 
confiabilidade das escalas foi medida por meio do índice de Alpha de Cronbach. Cabe destacar que, neste estudo os alfas variaram de 0,69 a 0,91 para os construtos, o que a garante uma boa confiabilidade da pesquisa.

Para análise dos dados, para fins de comparação, adotou-se os mesmos procedimentos que constam no instrumento utilizado por Segala (2013). Os dados obtidos a partir dos questionários foram quantitativamente analisados com emprego de estatísticas descritivas (média e análise de clusters). As análises foram realizadas com o auxílio dos softwares "Windows Excel", "Statistical Package for Social Science”, versão 18 e pelo "Statistical Analysis System”, versão 9.

A extração dos clusters considerou o cálculo da média das respostas dos indivíduos em relação à escala Likert de 5 pontos utilizada no instrumento de pesquisa. De posse das médias de cada construto, as mesmas foram padronizadas entre $0 \%$ a $100 \%$, sendo convencionados três agrupamentos distintos, quais sejam: alto, com média de $66,67 \%$ a $100 \%$, médio, com média de $33,34 \%$ a $66,66 \%$ e baixo, com média de $0 \%$ a $33,33 \%$.

\section{Resultados e Discussões}

Para verificar e caracterizar o perfil dos participantes da pesquisa utilizou-se o método estatístico descritivo, por meio da distribuição de frequências e cálculos das médias. Para dar maior consistência ao comparativo, as características da amostra participante do estudo encontram-se na Tabela 1.

Tabela 1: Características da amostra

\begin{tabular}{l|c|c}
\multicolumn{1}{c}{ VARIÁVEIS } & $\begin{array}{c}\text { TOTAL IES A } \\
(\mathbf{N = 1 6 2})\end{array}$ & $\begin{array}{c}\text { TOTAL IES B } \\
\text { (N=268) }\end{array}$ \\
SEXO (\%) & $\mathbf{5 6 , 7 9}$ & 49,25 \\
\hline Masculino & 43,21 & 50,75 \\
\hline Feminino & & \\
\hline Até 30 anos & 20,37 & 11,19 \\
\hline 31 a 45 anos & 24,07 & 27,24 \\
\hline 46 anos ou mais & 55,56 & $\mathbf{6 1 , 5 7}$ \\
\hline ESCOLARIDADE (\%) & & 1,12 \\
\hline au & 0,62 & 11,19 \\
\hline au & 22,22 & 36,57 \\
\hline au & 50,62 & $\mathbf{5 1 , 1 2}$ \\
\hline Juduação & 26,54 & \\
\hline TEMPO DE SERVIÇO & & 32,09 \\
\hline Até 8 anos & 34,57 & 19,40 \\
\hline De 9 a 20 anos & 7,41 & 48,51 \\
\hline \multicolumn{1}{|c|}{ Acima de 21 anos } & $\mathbf{5 8 , 0 2}$ & \\
\hline
\end{tabular}

Fonte: Dados da pesquisa.

Observa-se, na Tabela 1, que, com relação a caracterização da amostra, a maioria da amostra é do sexo masculino $(56,79 \%)$ na IES A e feminino na IES B (50,75\%). Quanto à idade, os dados coletados revelam que mais da metade dos entrevistados da IES B $(61,57 \%)$ e IES A $(55,56 \%)$ estão na faixa etária acima dos 46 anos. No quesito escolaridade, há um predomínio dos que possuem pós-graduação na IES B $(51,12 \%)$ e graduação na IES A (50,62\%). Os que ocupam cargos de nível médio são $64,55 \%$ na IES B e $80,86 \%$ na IES A.

\subsection{Comparação entre os níveis de Comprometimento e Entrincheiramento}

Na Tabela 2 apresenta-se os resultados obtidos para avaliar os dos níveis de comprometimento entre a IES A e a IES B.

Tabela 2: Comparativo do vínculo de comprometimento

\begin{tabular}{|c|c|c|c|c|c|c}
\hline \multirow{2}{*}{ VÍNCULOS } & \multicolumn{3}{|c|}{ IES A } & \multicolumn{3}{c}{ IES B } \\
\cline { 2 - 6 } & BAIXO & MÉDIO & ALTO & BAIXO & MÉDIO & ALTO \\
\hline Comprometimento Afetivo & $0,00 \%$ & $27,16 \%$ & $\mathbf{7 2 , 8 4 \%}$ & $2,24 \%$ & $42,91 \%$ & $\mathbf{5 4 , 8 5 \%}$ \\
\hline
\end{tabular}




\begin{tabular}{c|c|c|c|c|c|c}
\hline Comprometimento Instrumental & $2,47 \%$ & $21,60 \%$ & $\mathbf{7 5 , 9 3 \%}$ & $12,69 \%$ & $\mathbf{4 9 , 6 3 \%}$ & $37,69 \%$ \\
\hline Comprometimento Normativo & $8,02 \%$ & $\mathbf{5 8 , 0 2} \%$ & $33,95 \%$ & $\mathbf{4 9 , 2 5 \%}$ & $43,28 \%$ & $7,46 \%$ \\
\hline
\end{tabular}

Fonte: Dados da pesquisa.

De acordo com os dados apresentados na Tabela 2, percebe-se que dos 162 servidores entrevistados na IES A, no geral, 72,84\% apresentam um vínculo afetivo alto, o que revela uma união envolvendo uma relação ativa entre servidores e instituição. Quanto à IES B, observa-se que, dos 268 servidores entrevistados, no geral 54,85\% apresentaram um vínculo afetivo também alto. Comparando os dados das duas instituições, observa-se que ambas apresentaram um vínculo afetivo alto, com predomínio para a IES A, que apresentou um percentual geral de $72,84 \%$ contra 54,85\% da IES B. Segundo Mowday, Porter e Steers (1982), a noção de afeto para com a organização estimula o indivíduo a permanecer porque gosta, compartilha valores e se envolve com os papéis organizacionais. Além disso, para Meyer e Allen (1991), os indivíduos criam uma relação de apego e envolvimento com a organização.

Aceca do comprometimento instrumental, verifica-se que, no geral, 75,93\% dos servidores da IES A manifestaram um comprometimento instrumental alto, $21,6 \%$, mediano e 2,47\%, baixo. Nos dados da IES B, por sua vez, no geral, evidencia-se que $49,63 \%$ dos servidores apresentam comprometimento instrumental médio, 37,69\%, alto e $12,69 \%$, baixo. Quando confrontados os dados das duas instituições, percebe-se que variam entre alto e médio, e isso sugere, de acordo com Bastos (1994), a existência de uma forma de apego psicológico, na qual o indivíduo considera que sua saída da organização representa um alto custo ou sacrifícios significativos, tanto de ordem econômica, como social ou psicológica.

Dentro desse quadro, e considerando as oportunidades diferentes, ocasionadas pelas diferenças regionais que influem nas realidades das duas instituições, justificando, assim, os percentuais mais altos de comprometimento instrumental obtidos na IES A, é oportuno fazer uma reflexão mais profunda a respeito dos trabalhos de Becker (1960), quando descrevem que o indivíduo permanece na organização analisando custos versus benefícios associados à sua saída. No momento em que perceber mais vantagens na saída, ele provavelmente deixará a organização. Segundo Siqueira (2001), este comprometimento pode ser enquadrado no âmbito do comportamento, no qual o trabalhador permanece na organização por percepções individuais sobre os custos ou perdas de investimentos.

Já com relação ao comprometimento normativo, constata-se que, no geral, 58,02\% dos servidores da IES A apresentaram um comprometimento normativo médio. Em seguida, aparecem 33,95\% dos servidores com comprometimento normativo alto. Apenas $8,02 \%$ dos servidores apresentaram um vínculo normativo baixo. $\mathrm{Na}$ IES B, os dados evidenciam que 49,25\% dos servidores possuem um comprometimento normativo baixo, $43,28 \%$ médio e $7,46 \%$ alto.

$\mathrm{Na}$ análise comparativa, inicialmente é importante destacar que a internalização das normas com razão de permanência varia entre um patamar que vai de médio a alto na IES A, enquanto que, na IES B, a variação fica entre médio e baixo. Isso sugere, conforme Meyer e Allen (1991), que os servidores que apresentam alto grau de comprometimento normativo permanecem na organização porque sentem obrigação de ficar. Mergulhando-se nas reflexões de Bastos (1994), constata-se que as organizações possuem diversas formas de fazer com que seus funcionários sintam que não podem abandoná-la, como clubes de campo, onde existe grande contato entre os membros, formando uma grande família e por meio de fortes regras de conduta e forte missão, fazem com que o indivíduo pense que ela necessita dele para continuar com seus projetos. Assim, segundo Siqueira (2001), há uma propensão do indivíduo para se guiar por valores culturais internalizados, sem se dar conta de quão pouco racionais certas ações possam parecer.

Diante destes resultados, é possível encontrar, num determinado indivíduo, dimensões diversificadas de comprometimento, como, por exemplo, uma forte necessidade (instrumental), uma forte obrigação (normativo) e um baixo desejo (afetivo) de permanecer na organização, sugerindo a possibilidade de existir combinação de níveis das três dimensões na composição de um estado de comprometimento organizacional.

Na Tabela 3 apresenta-se os resultados obtidos para avaliar os níveis de entrincheiramento entre a IES A e a IES B.

Tabela 3: Comparativo do vínculo de entrincheiramento

\begin{tabular}{|l|c|c|c|c|c|c}
\hline \multirow{2}{*}{ ENTRINCHEIRAMENTO } & \multicolumn{3}{|c|}{ IES A } & \multicolumn{3}{c}{ IES B } \\
\cline { 2 - 7 } & BAIXO & MÉDIO & ALTO & BAIXO & MÉDIO & ALTO \\
\hline Ajuste à posição social & $0,00 \%$ & $27,16 \%$ & $\mathbf{7 2 , 8 4 \%}$ & $37,31 \%$ & $\mathbf{5 3 , 3 6 \%}$ & $9,33 \%$ \\
\hline
\end{tabular}


http://www.revista.ufpe.br/gestaoorg

\begin{tabular}{l|c|c|c|c|c|c}
\hline Limitação de alternativas & $5,56 \%$ & $\mathbf{6 5 , 4 3 \%}$ & $29,01 \%$ & $31,72 \%$ & $\mathbf{6 1 , 9 4 \%}$ & $6,34 \%$ \\
\hline Arranjos burocráticos impessoais & $0,62 \%$ & $24,69 \%$ & $\mathbf{7 4 , 6 9 \%}$ & $11,57 \%$ & $\mathbf{5 8 , 9 6 \%}$ & $29,48 \%$ \\
\hline
\end{tabular}

Fonte: Dados da pesquisa.

Analisando os dados das duas instituições, constata-se que a maioria da amostra da IES A apresentou um alto grau de entrincheiramento na dimensão ajustamento a posição social (72,84\%), enquanto que, na IES B, os maiores percentuais foram observados no cluster médio (53,36\%), o que revela que os servidores da IES A teriam mais problemas em se adaptarem a novas condições de trabalho, caso mudassem de organização, e , por outro lado, os servidores da IES B demonstraram certo receio em relação aos ajustes que deveriam fazer para serem reconhecidos em outra organização, conhecer os seus processos e as atribuições ao mudar de organização. Chama a atenção que, no grau baixo, nenhum participante da amostra da IES A não considera um problema deixar a instituição, pois está em um grau baixo de entrincheiramento, em contraste aos $37,31 \%$ da IES B, nesse mesmo fator.

Com base na literatura pesquisada, é importante destacar que, nos ajustamentos a posições sociais, tanto o profissional quanto à organização realiza investimentos, a fim de que determinada atividade seja bem desenvolvida, o trabalhador se adapte à posição em que se encontra (RODRIGUES, 2009). Segundo Scheible e Bastos (2013), quando isso ocorre, os indivíduos não são motivados a considerar outras alternativas de trabalho. O comportamento do indivíduo é fixado de acordo com o papel social exigido, fica em uma posição confortável, acredita ter bom desempenho, é reconhecido por sua função na organização e ali permanece.

Acerca da dimensão limitações de alternativas identificou-se que, a maior parte dos servidores da IES B $(61,94 \%)$ percebe como média as suas limitações de alternativas. O percentual geral de $31,72 \%$ refere-se os servidores que percebem como baixo o seu entrincheiramento, nessa dimensão. Por último, estão os servidores que percebem como altas as suas limitações de alternativas, com 6,34\%. De acordo com os achados, ambas as instituições apresentaram um entrincheiramento limitação de alternativas em nível mediano. Na limitação de alternativas, o indivíduo sente a sensação de estar entrincheirado na organização, devido à ausência de alternativas, pois verifica que não há espaço no mercado de trabalho, por conta da sua idade, limitação de conhecimentos etc. (RODRIGUES, 2009).

Quando comparados os dados das duas instituições, constata-se uma variação de média à alta, na IES A, e de média à baixa na IES B. Apesar de ambas as instituições perceberem de forma moderada seu entrincheiramento com relação a essa dimensão, há uma tendência maior da IES A em considerar suas limitações, tornando relevante estudar o motivo de o empregado tornar-se ou manter-se entrincheirado. Essas motivações implicam em algumas consequências negativas para a organização, uma vez que empregados entrincheirados e descontentes não contribuirão e nem se esforçarão, não estarão engajados nos seus projetos, podendo comprometer o crescimento e os rendimentos da organização (CARSON; CARSON; BEDEIAN, 1995). Assim, os indivíduos permanecem na organização devido a sua avaliação acerca de sua empregabilidade, de suas alternativas restritas fora dela e dos custos associados à sua saída (RODRIGUES; BASTOS, 2011).

Os resultados para dimensão arranjos burocráticos impessoais, em relação à amostra da IES A, a maioria dos entrevistados (74,69\%) apresentou um entrincheiramento alto, ou seja, temem perder os benefícios obtidos. Ainda, $24,69 \%$ apresentaram um nível médio de entrincheiramento com relação a esse fator e apenas $0,62 \%$ da amostra deixaria, sem problemas, a organização, pois aspectos como estabilidade financeira e outros benefícios não lhes causariam graves danos. A IES B apresenta um percentual geral de 58,96\% de entrincheiramento arranjos burocráticos impessoais médio, seguido de $29,48 \%$ de entrincheiramento alto e $11,57 \%$, de dos servidores estão no nível baixo de ajuste à posição social.

Nesse tipo de entrincheiramento, arranjos burocráticos impessoais, os dados encontrados evidenciaram uma variação entre os níveis médio e alto, nas duas instituições, sendo que há predominância dos percentuais de níveis mais altos para a IES A (74,69\%). Esses dados sugerem que os profissionais temem perder a estabilidade, os ganhos financeiros e os benefícios adquiridos, como planos de saúde, odontológicos, aposentadoria, entre outros. Dessa forma, o trabalhador entrincheirado percebe que ao deixar a organização perderá muitos benefícios já conquistados e, por isso, permanece trabalhando.

\section{Considerações Finais}

Este estudo teve por objetivo comparar a percepção dos técnico-administrativos em educação de duas instituições de ensino superior acerca do estabelecimento dos vínculos de comprometimento e entrincheiramento com as suas organizações. A partir dos resultados foi possível verificar que o construto comprometimento organizacional apresentou uma tendência alta, revelando que a maioria dos servidores está disposta a se esforçar em benefício da 
instituição pesquisada. Quando os três fatores do construto foram analisados separadamente, na IES A, o afetivo e o instrumental apresentaram uma tendência alta, enquanto o normativo apresentou uma tendência média, mesclando a satisfação de pertencer à instituição com um moderado sentimento de obrigação em permanecer na organização. O que para Simon e Coltre (2012), pode ser explicado pelo o fato do trabalhador não achar certo, mesmo sendo vantajoso para ele, deixar a organização no presente momento, reforçando o sentimento de culpa caso a deixasse agora, a lealdade perante ela, a obrigação moral com as pessoas do seu trabalho e o sentimento de dever muito a organização.

Ao comparar os resultados da IES B, é interessante observar, inicialmente, que ambas apresentaram um comprometimento afetivo alto, revelando um apego emocional dos empregados com suas instituições, o que, para Siqueira e Gomide Jr. (2004), pode caracterizar envolvimento e identificação com as mesmas e proporcionar um baixo absenteísmo e rotatividade nas respectivas organizações.

O comprometimento instrumental apresentou uma variação de alta a média entre as duas instituições, evidenciando o grau que a amostra pesquisada considera os custos associados a deixar a organização. Quanto ao comprometimento normativo, a variação é entre média, na IES A, e baixa a média, na IES B, revelando que a amostra pesquisada tende a contribuir positivamente com a organização. Entretanto, os sentimentos de obrigação não permitem que demonstrem o mesmo entusiasmo e envolvimento que o apresentado por um indivíduo com laço afetivo.

De uma forma geral, esses resultados revelaram que as instituições têm um imenso significado para seus servidores, os quais se interessam pelo destino da mesma e sentem-se orgulhosos em demonstrar essa satisfação. Esse vínculo, para é benéfico para as organizações e os empregados comprometidos, pois o conceito de comprometimento organizacional está ligado ao bem-estar no trabalho e à satisfação do trabalhador (FERRAZ; SIQUEIRA, 2006), assim como a maiores níveis de desempenho do indivíduo no trabalho (TOMAZZONI, 2017).

Quanto aos níveis de entrincheiramento organizacional, a maioria dos servidores pesquisados apresentou um percentual alto na IES A, seguidos dos que apresentaram percentuais médios. O que, de acordo com Carson, Carson e Bedeian (1995), não é bom nem para a organização nem para o profissional. Quando observa-se os resultados da IES B, é importante notar que a maioria dos pesquisados apresentou um percentual moderado, sugerindo, segundo Segala (2013), que o medo de deixar a organização estaria ligado às perdas de vantagens financeiras e à estabilidade, garantida após três anos de exercício efetivo, conforme contrato de trabalho estatutário (Regime Jurídico Único). Essa variação, média para IES B e alta para a IES A, não é interessante para essas instituições, pois implicam em algumas consequências negativas para ambas, uma vez que indivíduos entrincheirados e descontentes com seu trabalho, para Carson, Carson e Bedeian (1995), não contribuirão, não se esforçarão e não estarão engajados nos projetos das instituições para as quais trabalham, podendo comprometer o seu crescimento e o seu rendimento.

Como contribuição, este trabalho deixa um comparativo sobre a percepção dos servidores técnico-administrativos de duas instituições federais de ensino superior em relação aos tipos de vínculos de comprometimento e entrincheiramento organizacionais. A proposição aqui desenvolvida poderá ser reaplicada em outras instituições, de diferentes regiões, de natureza pública e privada, inseridas em contextos também distintos, permitindo a comparação dos resultados aqui encontrados. Esse trabalho deixa uma contribuição ao ajudar na síntese das teorias e modelos do comprometimento organizacional. Essa revisão acerca do comprometimento possibilitou a análise da dimensionalidade do construto e a sua configuração com outros vínculos organizacional, como o entrincheiramento, recentemente introduzido na literatura do campo do comportamento organizacional. Depois de um longo período em que a pesquisa sobre os vínculos do trabalhador com a organização esteve focada, quase que exclusivamente, no construto do comprometimento, a nova perspectiva de múltiplos vínculos organizacionais é reforçada com os resultados desta pesquisa, que verificou a coexistência de níveis de comprometimento e entrincheiramento nas duas instituições pesquisadas.

Consciente de que inacabado é próprio da sua condição inovadora, pois um modelo de organização de trabalho, quando esgota suas potencialidades, cede lugar a outro modelo qualitativamente superior que, por sua vez, também não será definitivo, é que se espera que este trabalho contribua para futuros estudos relacionados aos temas aqui abordados.

Face aos resultados obtidos, bem como a carência de estudos sobre a temática, principalmente sobre o entrincheiramento, é proposta uma agenda de pesquisa de modo que sejam realizadas novas investigações sobre o tema em outras instituições de realidades diferentes e ainda em outros tipos de organizações, com outras categoriais profissionais, que permitam entender melhor e contribuam para o refinamento conceitual dos fenômenos. Além disso, procurar complementar os achados aqui encontrados com amostras mais representativas da população brasileira que podem explicitar melhor as relações particulares; por meio de abordagens mais flexíveis, incluindo a análise qualitativa (entrevistas em profundidade, por exemplo; e com a utilização de uma abordagem 
longitudinal, a qual permitiria uma visão mais densa do tema em pauta).

\section{Referências}

AYREE, S.; CHAY, Y.; CHEW, J. An investigation of de predictors and outcomes of career commitment in three career stages. Journal of Vocation Behavior, v. 44, p. 1-16, 1994 . Available from: https://www.sciencedirect.com/science/article/abs/pii/S0001879184710013. Access: 24 jul. 2017.

ANDRADE, D. C. T.; PENHA, R.; RAMOS, H. R. Um estudo sobre a percepção de servidores públicos acerca do nível de socialização organizacional. In: ENCONTRO NACIONAL DA ANPAD, 38., Rio de Janeiro, 2014. Anais... Rio de Janeiro, 2014.

BASTOS, A. V. B. Comprometimento no trabalho: a estrutura dos vínculos do trabalhador com a organização, a carreira e o sindicato. 1994. 313 f. Tese (Doutorado em Psicologia)-Universidade de Brasília, Brasília, 1994.

BAStos, A. V. B.; SIQUeIRA, M. M. M.; MEDEIROS, C. A.; MENEZES, I. G. Comprometimento organizacional. In: SIQUEIRA, M. M. M. (Org.). Medidas de comportamento organizacional: ferramentas de diagnóstico e de gestão. Porto Alegre: Artmed, 2008.

BASTOS, A. V. B.; PINHO, A. P. M.; AGUIAR, C. V. N.; MENESES, I. G. Comprometimento organizacional: aprimoramento e evidências de validade do modelo tridimensional de Meyer e Allen no contexto brasileiro. In: ZANELLI, J. C.; SILVA, N.; TOLFO, S. R. (Orgs.). Processos psicossociais nas organizações e no trabalho. São Paulo: Casa do Psicólogo, 2011.

BECKER, H. S. Notes on the concept of commitment. The American Journal of Sociology, v. 66, n. 1, p. 32-40, 1960.

BLAU, G. On assessing the construct validity of two multidimensional constructs: Occupational commitment and occupational entrenchment. Human Resource Management Review, v. 11, p. 279-298, 2001. Available from: https://www.sciencedirect.com/science/article/abs/pii/S1053482200000528. Access: 15 jul. 2017.

BLAU, G.; HOLLADAY, E. B. Testing the discriminant validity of a four-dimensional occupational commitment measure. Journal of Occupational and Organizational Psychology, 79, 691-704, 2006. Available from: https://onlinelibrary.wiley.com/doi/abs/10.1348/096317905X69591. Access: 10 jun. 2017.

CARSON, K. D.; BEDEIAN, A. Career commitment: construction of a mesure and examination of its psychometric properties. Journal of Vocational Behavior, v. 3, n. 44, p. 237-262, 1994. Available from: https://www.sciencedirect.com/science/article/abs/pii/S0001879184710177. Access: 10 jan. 2017.

CARSON, K. D.; CARSON, P.; BEDEIAN, A. Development and construct validation of a career entrenchment measure. Journal of Occupational and Organizational Psychology, v. 68, p. 301-320, 1995. Available from: https://onlinelibrary.wiley.com/doi/abs/10.1111/j.2044-8325.1995.tb00589.x. Access: 16 jun. 2017.

CHIMEZIE, A. B; OSIGWEH, C. A. B. Concept fallibility in organizational science. Academy of Management Review, v. 14, n. 4, p. 579-594, 1989. Available from: https://www.jstor.org/stable/258560?seq=1\#page_scan_tab_contents. Access: 15 jun. 2017.

COHEN, A. Multiple commitments in the workplace: an integrative approach. Mahwah: Lawrence Erlbaum Associates, 2003.

COSTA, V. M. F. As influências de um programa de participação nos resultados no comprometimento organizacional: o caso de uma empresa gaúcha do ramo moveleiro. 2000. Dissertação (Mestrado em Administração) - Universidade Federal de Santa Catarina, Florianópolis, 2000.

As bases afetiva e instrumental do comprometimento organizacional: confrontando suas diferenças entre empresas e trabalhadores na agricultura irrigada do pólo Juazeiro/Petrolina. 2007. 270 f. Tese (Doutorado em Administração) - Universidade Federal da Bahia, Salvador, 2007.

FERRAZ, C. R.; SIQUEIRA, M. M. M. Bem-estar no trabalho: estudo com uma amostra de professores. In: GRUPO INTERINSTITUCIONAL DE PESQUISA BEM-ESTAR, SUPORTE E TRABALHO, 4, 2006, Uberlândia, Anais... Uberlândia: GIBEST, 2006.

FERREIRA, A. B. H. Novo dicionário Aurélio da Língua Portuguesa. 2. ed. Rio de Janeiro: Nova Fronteira, 1998. 
FERREIRA, M. A. L. Empregabilidade e side-bets: uma realidade dos estudantes de mestrado. 2011.80 f. Dissertação (Mestrado em Psicologia) - Universidade Lusófona de Humanidades e Tecnologia, Lisboa, 2011.

KANTER, R. M. Commitment and social organization: a study of commitment mechanisms in utopian communities. American Sociological Review, v. 33, n. 4, p. 499-517, 1968. Avaliable from: https://www.jstor.org/stable/2092438?seq=1\#page_scan_tab_contents. Access: 25 jun. 2017.

MEYER, J. P.; ALLEN, N. J. A three-component conceptualization of organization commitment. Human Resource Management Review, v. 1, n. 1, p. 61-89, 1991. Available from: https://www.sciencedirect.com/science/article/abs/pii/105348229190011Z. Access: 15 jul. 2017.

Commitment in the w/orkplace: theory, research and application. Advanced Topics in Organizational Behavior. Thousands Oaks: Sage Publications, 1997.

MEYER, J. P.; HERSCOVITCH, L. Commitment in the workplace: toward a general model. Human Resource Management Review, v. 11, p. 299-326, 2001. Available from: https://www.sciencedirect.com/science/article/abs/pii/S105348220000053X. Access: 12 jan. 2017.

MORROW, P. C. Concept redundancy in organizational research: the case of work commitment. Academy of Manegement Review, v. 8, p. 486-500, 1983. Avaiable from: http://amr.aom.org/content/8/3/486.abstract. Access: 23 jul. 2017.

MOWDAY, R. T.; PORTER, L. W.; STEERS, R. M. The measurement of organizational commitment. Journal of Vocational Behavior, $\quad$ v. $14, \quad$ p. 224-247, 1979. Available from: https://www.sciencedirect.com/science/article/abs/pii/0001879179900721. Access: 20 jan. 2017.

Employee-organization linkages: the psychology of commitment, absenteeism, and turnover. New York: Academic Press, 1982.

MULLER, M.; RAUSKI, E. F.; EYNG I. S.; MOREIRA, J. Comprometimento organizacional: um estudo de caso no supermercado "Beta". Revista Gestão Industrial, v. 4, n. 1, p. 511-518, 2008. Disponível em: https://periodicos.utfpr.edu.br/revistagi/article/view/146. Acesso em: 20 mai. 2017.

O'REILLY III, C.; CHATMAN, J. Organizational commitment and psychological attachment: the effects of compliance, identification, and internalization on prosocial behavior. Journal of Applied Psychological, v. 71, n. 3, p. 492-499, $1986 . \quad$ Available from: https://pdfs.semanticscholar.org/1eef/c51ff886acd6f2c317f8f25a3f42fe984ddb.pdf. Access: 10 jul. 2017.

PINHO, A. P. M.; BASTOS, A. V. B.; ROWE, D. E. O. Diferentes Vínculos Indivíduo-Organização: Explorando Seus Significados entre Gestores. Revista de Administração Contemporânea, v. 19, n. 3, p. 288-304, 2015. Disponível em: http://www.scielo.br/scielo.php?script=sci_arttext\&pid=S141565552015000900004\&lng=pt\&tlng=pt\#aff3. Acesso em: 13 ago. 2017.

REICHERS, A. E. A review and reconceptualization of organizational commitment. Academy of Management Review, $\quad$ v. $10, \quad$ p. $465-476, \quad 1985 . \quad$ Available from: https://www.jstor.org/stable/258128?seq=1\#page_scan_tab_contents. Access: 14 ago. 2017.

RITZER, G.; TRICE, H. M. An empirical study of Howard Becker's side-bet theory. Social Forces, v. 47, p. 475 479, 1969. Available from: https://www.jstor.org/stable/2574537?seq=1\#page_scan_tab_contents. Access: 15 jan. 2017.

RODRIGUES, A. C. A. Do comprometimento de continuação ao entrincheiramento organizacional: o percurso de validação da escala e análise da sobreposição entre os construtos. 2009. 212 f. Dissertação (Mestrado em Psicologia) - Universidade Federal da Bahia, Salvador, 2009.

RODRIGUES, A. C. A. BAStOS, A. V. B. Do comprometimento de Continuação ao Entrincheiramento Organizacional: Evidências de Sobreposição entre os Construtos. In: ENCONTRO DA ANPAD, 35, 2011 Rio de Janeiro. Anais... Rio de Janeiro: ANPAD, 2011.

RODRIGUES, A. C. A. BASTOS, A. V. B. Entrincheiramento organizacional: construção e validação da escala. Psicologia e Reflexão Crítica, v. 25, n. 1, p. 688-700, 2012. Disponível em: http://www.scielo.br/scielo.php?script=sci_arttext\&pid=S0102-79722012000400008. Acesso em 15 mar. 2017.

RODRIGUES, A. C. A.; GODIM, S. G. M.; BASTOS. A. V. B.; SAKAMOTO, R. Como se Constroem e se Desenvolvem o Entrincheiramento e o Comprometimento com a Organização: Análise Qualitativa de Diferentes Trajetórias Profissionais. In: ENCONTRO DA ANPAD, 37, 2013, Rio de Janeiro. Anais... Rio de Janeiro: 
ANPAD, 2013.

RODRIGUES, A. P. G.; BASTOS, A. V. B.; GODIM, S. M. G. Comprometimento, entrincheiramento e regulação emocional em trabalhadores do serviço público. Revista Científica Hermes, v. 8, 2013, p. 23-46. Disponível em: <file://C:/Users/Gean/Downloads/ 72-144-1-SM.pdf>. Acesso em: 10 mai. 2017.

ROWE, D. E. O.; BASTOS, A. V. B.; PINHO, A. P. M. Comprometimento e entrincheiramento na carreira: um estudo de suas influências no esforço instrucional do docente do ensino superior. Revista de Administração Contemporânea, Curitiba, v. 15, n. 6, p. 973-992, nov./dez. 2011. Disponível em: http://www.scielo.br/scielo.php?pid=S141565552011000600002\&script=sci_arttext. Acesso em: 10 mai. 2017.

SEGALA, V. Relação entre o modelo de gestão de pessoas agency-community com os tipos de vínculos comprometimento e entrincheiramento organizacional. 2013. 104 f. Dissertação (Mestrado em Administração) - Universidade Federal de Santa Maria, Santa Maria, 2013.

SCHEIBLE, A. C. F.; BASTOS, A. V. B. An Examination of Human Resource Management Practices' Influence on Organizational Commitment and Entrenchment. Brazilian Administration Review, Rio de Janeiro, v. 10, n. 1, p. 57-76, 2013. Disponível em: http://www.redalyc.org/articulo.oa?id=84124875005>. Acesso em: 25 fev. 2017.

SIMON, J.; COLTRE. S. M. O Comprometimento Organizacional Afetivo, Instrumental e Normativo: estudo de caso de uma empresa familiar. Qualit@s Revista Eletrônica, v. 13, n. 1, p. 4-23, 2012. Disponível em: http://revista.uepb.edu.br/index.php/qualitas/article/view/1338. Acesso em: 23 abr. 2017.

SIQUEIRA, M. M. M. Comprometimento Organizacional Afetivo, Calculativo e Normativo: Evidências Acerca da Validade Discriminante de Três Medidas Brasileiras. In: ENCONTRO DA ANPAD, 25, 2001, Campinas. Anais... Campinas: ANPAD, 2001.

SIQUEIRA, M. M. M.; GOMIDE Jr., S. Vínculos do indivíduo com a organização e com o trabalho. In: ZANELLI, J. C.; BORGES-ANDRADE, J. E.; BASTOS, A. V. B. (Orgs.). Psicologia, organizações e trabalho. Porto Alegre: Artmed, p. 300-328, 2004.

TEIXEIRA, M. G. Comprometimento organizacional: uma análise dos fatores individuais numa empresa de prestação de serviços. In: ENCONTRO DA ANPAD, 18, 1994, Curitiba, Anais... Curitiba: ANPAD, 1994.

TOMAZZONI, G. C. Vínculos de Comprometimento, Entrincheiramento e Consentimento do Indivíduo com a Organização: Explorando seus Antecedentes e Consequentes. 2017. 179 f. Dissertação (Mestrado em Administração)-Universidade Federal de Santa Maria, Santa Maria, 2017.

TOMAZZONI, G. C.; COSTA, V. M. F.; SANTOS, A. S.; ESPICH, D.; POSSER, T. G. O processo de efetivação o servidor: um estudo acerca do estágio probatório nas universidades. Revista GUAL, v. 10, n. 1, p. 62-78, 2017. Disponível em: https://periodicos.ufsc.br/index.php/gual/article/view/1983-4535.2017v10n1p62/33542. Acesso em: 23 jan. 2018.

TONIN, S.; TONIN G. A.; FREITAS, L. A. R.; COSTA, V. F. Comprometimento e entrincheiramento organizacional: um estudo de suas relações em uma organização do setor comercial. In: SEMINÁRIOS EM ADMINISTRAÇÃO - FEA/USP, 15, 2012, São Paulo. Anais... São Paulo: SEMEAD, 2012. 